\title{
Can We Synthesise Different Development Theories?
}

\section{Gilbert Ahamer}

\author{
Graz University
}

\begin{abstract}
Different ideas of 'development' provide different recommendations for socio-political action. Because of this self-evident fact, an attempt is made to bring together antagonistic systems of understanding of 'development' from an evolutionary perspective in a discursive manner, ultimately to gain greater acceptance for the resulting basic strategies in different camps. Attitudes that are either optimistic or critical regarding the chances of 'development' (so-called 'preanalytic visions') are described on the basis of (i) literature (Section 2) and (ii) data (Section 3) and the resulting recommendations for action are compared with each other.

As an attempt at mediation between both paradigms, an original conception inspired by evolutionary thinking is proposed here: based on the data structures of the author's 'Global Change Data Base' $(G C D B)$, a long-term dynamic of global techno-socio-economic development can be assumed which is characterised by a succession of initially growing and then saturating structural parameters. Particularly in the energy industry and land use, such a sequence of initially budding, then blossoming and finally maturing development phases (= 'blossoming evolution') seems to be present if the data sets of all states are analysed in the long term (Section 4). A thinking in transitions (Section 5, 6) thus appears justified, appropriate and helpful.

In this sense, any strategic climate or development policy measure is based on an already ongoing (rolling) global structural change. In the light of the concept of 'blossoming evolution,' it therefore seems helpful (as well as easier to implement) to reinforce or mitigate such alreadyoccurring evolutionary dynamics in a suitable way in order to come as close as possible to the goals of sustainable global development.
\end{abstract}

Social Evolution \& History, Vol. 20 No. 2, September 2021 79-108

(C) 2021 'Uchitel' Publishing House

DOI: $10.30884 / \mathrm{seh} / 2021.02 .04$ 
Summing up, this text suggests that any developmental measures should be placed in a suitable context of evolutionary autopoietic dynamics, which is in any case driving history.

Keywords: socio-economic evolution, development theory, transition, global change, evolutionary view, blossoming evolution, Global Change Data Base GCDB.

\section{INTRODUCTION}

The purpose of this paper is to offer a fresh perception on development theories with an additional perspective on evolution. Therefore, the following text uses the languages of several scientific disciplines.

The desire of the author of this text is to offer concepts of thought that may seem at the same time both familiar and unfamiliar to persons with a background in either natural or social sciences. The desired result is to merge both these sources for scientific paradigms. In this sense, the language of this article borrows from mathematics, ecology, biology, pedagogy and technology to ensure that readers encounter partially familiar, even if sometimes unknown, considerations. Intentionally, the terminology is not disciplinary in the classical sense but uses thought patterns that are independent from disciplines and stem from systems analysis, such as the terms evolution, saturation, and structures. Readers are therefore kindly asked to muster the courage and have the willingness to leave their respective conceptual homeland behind.

Be our point of departure scientific or sociological, in this text our focus will keep wandering from the cabinets of contradictory individual views and theories (in Ancient Greek, theoreia = contemplation) into a world in which 'the supposedly different takes place' (Novy 2008: 2). However, it remains 'different' only if the participation in common consciousness is not perceived (see Moser 2017, 2018a, 2018 b) and if common understanding is not possible.

This article takes an analysis of long-term global trends as a case study for a discussion on economic growth, energy consumption and the term 'development' per se. The outcome of the study will be that global evolution responds to challenges such as climate change through building up structures.

The reasoning of the importance of energy and land use for the discussion on Global Change is given in Fig. 1. The main thread of action from the economy to $\mathrm{CO}_{2}$ emissions to climate change is the central theme of all considerations and is also in line with the DPSIR (driver-pressure-state-impact-response) model of the European Environment Agency EEA (2005: 357ff). The global system response to climate change - that is, the feedback - takes the path of structure 
formation and structural change, as a look at globally emerging institutions such as the IPCC and UNFCCC confirms. The topic "climate change' is the cause and crystallization of new global structure formation in the sense of the evolving 'noosphere' invented by both Pierre Teilhard de Chardin (1969: 193f) and Vladimir Vernadsky (1986 [1926]).

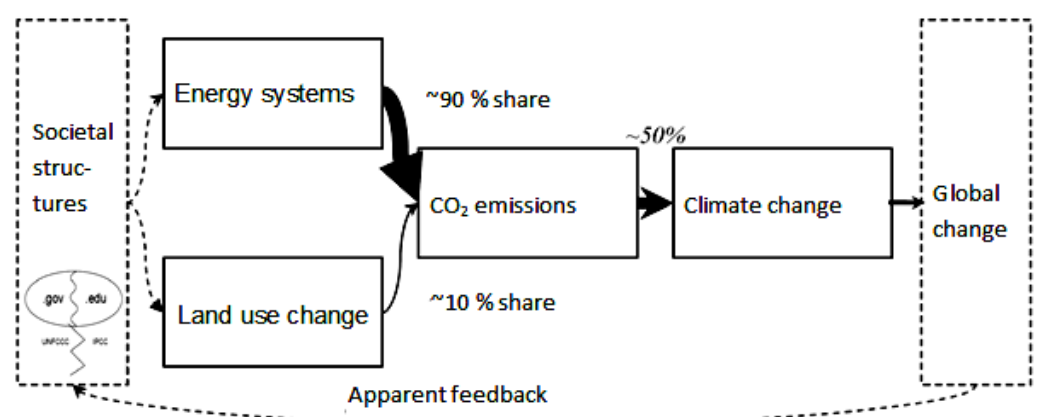

Fig. 1. The setting of this contribution along the main causal chain in the impact pattern 'climate change,' the 'red thread.'

Social structures are divided into the 'complementary hemispheres' administration / government and universities / research (insert below left). The energy industry is the main cause of $\mathrm{CO}_{2}$ emissions, which in turn causes climate change

The fusion of different disciplines is the focus of Globalistics and Global Studies which is a synergistic academic discipline, as inter alia highly promoted by several groups of Russian authors (Bondarenko et al. 2002; Bondarenko 2007: 193; 2009: 50; 2011: 122-123), contemplating and analysing history's evolutionary dynamics while jointly viewing mental, social, and political levels. Interestingly, that thread of research results in a 'final result' that is identical to the result of research presented here: 'the most important of these insights concerns the nature of the emerging worldview' (Baskin and Bondarenko 2018: 1); thus, emphasising the creative power of views and consciousness as such (Capra 2010; Lipton 2015; Ahamer 2019). All these approaches suggest a "non-linear, "processual" model of the emerging world' (Baskin and Bondarenko 2018: 1; Whitehead 1979) at the expense of static, linear history that can no more be explained by power relations alone, but by co-evolutionary dynamics. For these authors, 'Complexity theory studies the patterns that emerge as phenomena evolve in a processual world' (Ibid.). 
As a point of start for this article's practical reasoning, the common thread in Fig. 1 accordingly runs through interdisciplinary areas from institutional (far left) to economic (left), science (centre) and living space issues (right) such as global change. The ultimate conclusion of the interdisciplinary work in this article will be the encouragement to 'dialogue and discourse as a fundamental method.' Discourse here is a methodical attitude (Ahamer 2013a, 2013b), among other reasons based on analyses of previous intercultural work of the author (Ahamer and Kumpfmüller 2013; Ahamer and Jekel 2010; Ahamer and Schrei 2006). Knowledge only comes when all perspectives are made use of. This is the fundamental meaning of the term 'meta-geography' coined in the recent book 'Mapping Global Dynamics' (Ahamer 2019).

It is not the intent of this text to present another, separate, 'correct' world view, but the goal is to present a conceptual vessel for different and often contradictory worldviews that allows the integration of concepts that are contradictory at first glance. The point is to see that in the evolution of structures and different worldviews, it is possible and even principally true that formerly antagonistic theories are merging.

The ultimate question is: 'How do structures come into being?', even if 'structures' is a term outside of the traditional classical worldview of natural science. In our globalisation context, the arising practical question will be: how can global institutions grow and be promoted in such a way that they meet our socially sustainable developmental ideals?

This fits a symbolic analogy for the essence of 'development' in the field of education:

1. Encourage, hence strengthen internal motivation

2. Demand, hence strengthen external motivation.

Since the Swiss pedagogue Pestalozzi, pedagogy has kept talking about 'children gardeners.' Like a mediator between two contrary world views, the term 'gardener' has the meaning of a careful, naturefriendly and beneficial intervention. Similarly, we could speak of 'school gardeners.' Why not speak on a global level of 'world gardeners'? This would be the role of the human being which will justify all the diverse developmental ideas presented in this text.

\section{DEVELOPMENT: CONVERGENCE OR DIVERGENCE?}

\subsection{A Traditional Literature Search}

The present analysis starts with a scan of the flagships of classical international economic growth literature. At the centre is the hardcore 
term 'development', as this concept is a central driver of global change.

If development is intended to be a worthwhile goal, then it should not counteract other goals such as global justice. Therefore, the actual and real convergence of development (which is a key tenet of neoclassical development economics) - that means, reaching a similar GDP per capita (gross domestic product per capita) across all nations worldwide merely by normal economic evolution - is a litmus test of the human legitimacy of the policy objective 'material development'.

What actually is development? What do we mean and intend by development? This corresponds with the question 'What is our goal?' 'Development' is one of the central themes of this journal as well as the topic of a branch of economics with extensive literature, namely the so-called growth literature. This compound of scientific literature usually asks 'How do we get there the fastest?' (namely, to purely economic development, which is seen here in a positive way) and therefore the factors influencing development are analysed, which represents the obvious and clearly desired goal in such paradigm.

At the same time, our topic 'Development Theories' also asks the questions: 'Where do we want to go?' and 'How do we get there?' While reading this article and based on our backgrounds as critical citizens, we might not be so sure whether we should really want 'development' in the usual classic sense - but let us still look at the object of our hesitancy through old-fashioned glasses. It could sharpen and cultivate our will, and that is what we strive for.

A literature search was undertaken in the most prestigious economic literature, namely in the world's highest ranked economics journals. These have been ranked in economics by the impact factor - quoted in brackets - according to Clarivate (earlier named ISI Thompson, 2005), and selected by nine out of 14 journals as the most technically appropriate: Journal of Economic Literature (5.2), Quarterly Journal of Economics (4.8), NBER Macroeconomic Annals (3.2), Journal of Economic Perspectives (2.7), Economic Policy (2.3), Journal of Political Economy (2.2), American Economic Review (1.9), Economy and Society (1.7) and additionally Ecological Economics. In this process, about 100 relevant journal articles were identified, which are listed in Annex 1 with their key thoughts and reproduced here with the gist of their message.

The findings on how to increase growth include expanding international trade (Acemoglu and Ventura 2002; Estevadeordal et al. 2003) and deepening international integration (Devereux and Lapham 1994) on investment in human capital (Barro 1991, 2001; Mankiw et al. 1992), in research and development (Grossman and Helpman 1994) 
and in technology (Romer 1990; Basu and Weil 1998), to the construction of financial systems (King and Levine 1993), a more even income distribution (Alesina and Rodrik 1994) and the promotion of institutions and democracy (Przeworsky and Limongi 1993; Mauro 1995).

Ayres (1996) asks the basic question 'Is growth ever needed?' and an evolutionary approach is taken by Rammel and Bergh (2003). The basic and eternal question: 'Is there convergence or divergence?', is eventually tackled by Hedenus and Azar (2005), Pritchett (1997) and Jones (1997) - and, as expected, they all come to different conclusions. Often, in the search for answers, only mathematical models are studied instead of verifiable reality. Thus, for many aspects quantitative descriptions are attempted, yet most of the time an impression of incomplete conceptions remains: only one or very few sub-mechanisms of the entire topic are perceived more or less successfully.

This article suggests twofold criticism of the approaches outlined in the above-mentioned articles:

(1) Taking theory as a starting point: A part of the studies is based on formula building, that is on the assumption that (a) the complex global reality can be sufficiently represented by the parameters contained in a model, and (b) that the logical linkage between the parameters - mostly represented by mathematical equations - sufficiently matches the real and observable relationships.

(2) Taking reality as a starting point: another part of the studies derives its facticity from a statistical analysis (correlation) of data obtained from reality; however, only the contributions of these proxy variables (= approximate descriptors, such as 'school attendance in \%' for the 'educational level') describe reality, leaving other components of reality undescribed.

In terms of ideas, 'input' into a 'black box' (i.e., a model with an unknown inner life, in this case a system of equations with an imaginary chain of cause and effect) generates 'output'. In this case, if more 'output' is desired, more 'input' must be given, similar to a chemical reaction. The plant is 'pulled' out of the soil and it does not develop independently on its own. It is 'classical developmental mechanics' a physical analogue would be 'classical mechanics'. The latter is understood by physicists as a theory that provides sufficiently accurate descriptions for 90 per cent of everyday applications, but not for all topics. According to this 'classical concept of truth', these cited studies often aim at 'being right' on a factual level - which is understandable ultimately because an opposing worldview would result in a fundamentally different practical (economic and developmental) policy. 
But the 'classical view' tends to forget about other factors of production (economically speaking) beyond the classical factors. The attempt to distil these other production factors for (economic) development from statistical correlates is partly successful but also in danger of failure, because the position within the self-controlled growth phase of an economy is not taken into account; that means it is assumed that all 'laws of nature' apply independently of place and time and equally for all growth periods of an economy.

This hypothesised invariance of truth through space and time, without their validity being affected, is one of the cornerstones of mathematical Cartesian science, whose formulaic laws have often been too quickly adopted as a paradigm for the social sciences. Such a purely 'Cartesian' view would translate into the practice of the educational sphere of life as follows (to give an example in order to highlight its inappropriateness): babies or children need the same type of support as adults. Obviously, however, facts and growth factors depend on the phase of life; similar to the organic growth of plants, which first form soft shoots and then wooden supporting structures. Such a (radically different), non-static view, in which the validity of so-called 'truths' and 'laws' depends on a (growth) phase, is allowed only within the view of 'blossoming evolution' (Section 3.2).

\subsection{Another View on 'Development'}

Overall, the incentive to adopt an antithesis to the Cartesian (Descartes 1997 [1632]) mechanistic understanding of growth and to be able to make a different diagnosis lies to a great extent in the decision of the viewers themselves on a selected viewing method - that is in the choice of the lens by the viewer - maybe one of the last remaining truly sovereign choices of a human.

But how can we find an opposing position to a classical-mechanistic concept of development and then justify it? We need to shift the emphasis towards the self-directed, autonomous production of own developmental achievements in the area concerned. Paradigms that are critical to a classical notion of development could lead there, as embodied by existing heterodox institutions.

\subsection{The Practical Need to Wear Multiple Glasses Simultaneously}

There is a need for dialogue between the antagonistic perspectives of development (namely one of them being optimistic regarding development, compared here with a merely mechanistic understanding, and another being critical regarding development) because quite obviously a different view (in Greek: theory) leads to different practical recom- 
mendations for action (in Greek: praxis). Different institutional networks tend to have different pre-defined understandings, different 'pre-cognitive visions', to use Schumpeter's vocabulary. So, 'development'

1. from an optimistic perspective occurs instead through targeted intervention from outside, through external control,

2. from a critical perspective, on the other hand, by internal selfregulation.

As a synthesis of these two main developmental approaches (optimistic and critical), a basic attitude of 'discourse and dialogue' is suggested here that mediates between narrow perspectives and resides on an evolutionary approach - always permitting a next step of more thorough understanding. Quite practically relevant, this means the strengthening of a discursive Civil Society and a (hopefully irreversible) 'applied structure formation' in the sense of the proposed evolutionary world view.

\section{DEVELOPMENT AS A 'BLOSSOMING EVOLUTION'}

\subsection{Findings of the Global Change Data Base (GCDB)}

An extensive global data analysis of land use, economic and energy data (Ahamer 1994, 2013c, 2014a, b, 2018; Ahamer and Mayer 2013, 2014) has provided some quantitative evidence based on three decades of data that some non-linear developments cannot be predicted by a black-box input-output-oriented model:

(a) The growth rate of the population is decreasing in most countries and seems to be doing so in a regular way ('population transition');

(b) Forest clearing operations in the industrialized countries likewise only just reached a maximum half a millennium ago (which, on the one hand, easily vanishes from memory and, on the other hand, occurred over a more protracted period of time). This puts the current thematic concentration of 'deforestation' in the so-called 'Third World' in a completely different light, namely as a 'usual' event in the course of the expansion of settlement areas over the course of civilizational history, and shows the current increase in forest area in Europe as an extension of this trend (in analogy called 'deforestation transition');

(c) A country-by-country analysis of the chain of effects 'Population - Food Demand - Food Production' shows that the individual subsections of this chain show sigmoidal patterns (i.e., slow increase strong rise - saturation phase), in successive order (Ahamer 2001); 
(d) The relative importance of specific economic sectors within the total GDP of an economy seems to increase and decrease in a regular manner depending on the level of GDP per capita; and

(e) The per capita energy demand (see Appendix 2) and the market shares of energy carriers in the global energy economy seem to rise and fall in regular movements (Marchetti and Nakićenović 1979; Nakićenović 1997), in an analogy called 'energy carrier transition.'

The preceding examples already suggest that different perspectives could be adopted over the course of organic evolutionary developments. For the purposes of Section 1, the basic methodology and intent of this paper is the 'Dialogue between two fundamentally different world views' - this, incidentally, is the title of the main work of Galileo Galilei (1982 [1632]), who did contribute to a more emancipated knowledge of the universe. His famous saying 'Eppur si mиоve' (in old Italian: 'and yet it moves,' namely the planet Earth around the Sun) is read here as: 'And yet evolution is progressing.'

\subsection{The Development Concept of 'Blossoming Evolution'}

Blossoming evolution is an evolutive process in which individual parameters produce a certain dynamic in a sequential manner, namely growth first and then entry into saturation.

An example of land use: The graphical presentation and analysis of GCDB agricultural data (see Ahamer 2019: 73-76) suggests that groups of states are passing through an imaginary path of low to high GDP/capita.

3. Data initially show an increase in the population growth rate (d/dt [Pop], which eventually remains constant and even decreases (the well-known population transition)

4. then, starting from low starting values, an increase in the percapita grain quantity for nutrition (d/dt [cereals food / cap]) takes place, which then also remains constant (saturation effect in the literal sense)

5. then data show a change in the nutritional structure towards higher meat content (d/dt [meat food / cereals food]), which is decreasing in the richest countries

6 . then the rate of increase in the distribution of cereals for other uses (d/dt [cereals supply / cereals food]) stabilizes again

7. then the growth rates in trading volumes increase $(\mathrm{d} / \mathrm{dt}$ [cereals production / cereals supply])

8. finally, agricultural area efficiency $(\mathrm{d} / \mathrm{dt}$ [cereals area harvested / cereals production]) improves (Ahamer 2019: ch. 7). 
It seems, therefore, that in the course of an - as always quantifiable - development, at least different sub-areas (here: population amount of food - food composition - food use - trade in food - production of food) of a total topic (here: 'global food demand and supply') are experienced successively. Each sub-range exhibits first low, then high, and finally again lower rates of increase. Mathematically and graphically, such a waveform described in words is identical to the so-called sigma curve; that is an initial increase with subsequent saturation. The sigma curve (named according to the Ancient Greek letter $\zeta$, which is the sigma letter variant used at word ends, in contrast to $\sigma$ within a word) symbolises the paradigm of 'limited growth' and can therefore be regarded as a logo for life processes par excellence. The curve increase in the rising phase is proportional to the 'already existing' (A) in the final phase, with the 'remaining' (Z) up to an assumed natural limit of the growth process (Fig. 2).

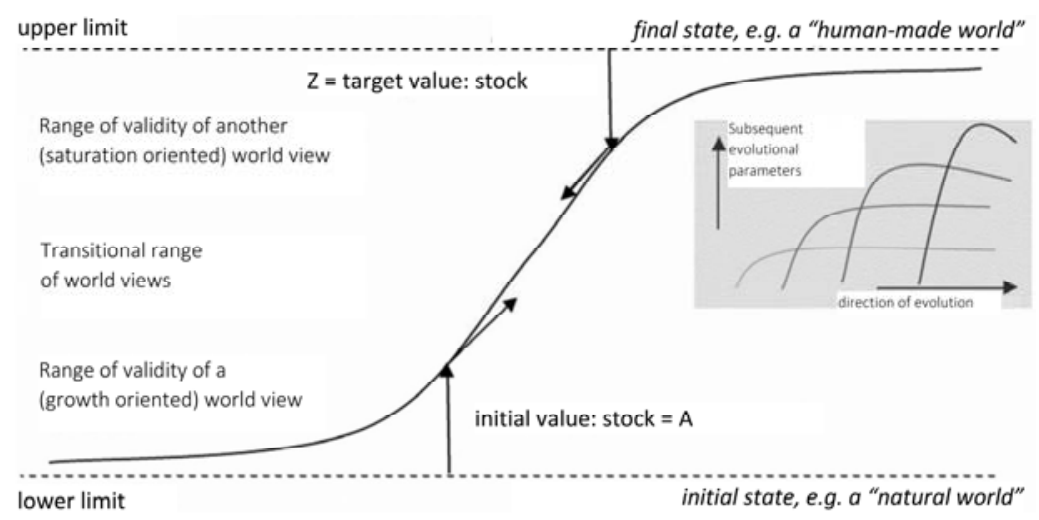

Fig. 2. Schematic sequence of any variable that moves within a limited range of values. Insert: successive 'blossoming' sequence in several developing parameters. The directions of optimization as well as the scope of worldviews change in the course of the phases

\subsection{Interpretations of the Blossoming Evolution}

The movement through the sigma curve could also be seen in conjunction with an increase in the relevance and subsequent decline of a topic in public perception. This perspective allows a synthesis between development-optimal attitudes (nourished if no growth limits are felt) and development-pessimistic attitudes (nourished when growth boundaries are felt) in the sense of an organic succession of seemingly contradictory theories. 
A comparison of these thought patterns with biological processes offers that similarly, a plant first forms the cotyledons (seed leaves), which are initially important for further growth. Then the stems, which are soft and green at first (symbolising 'quantitative', i.e., length growth), are created in a thrust, then two leaves on a first floor. Depending on the species, a second thrust of growth begins with the plant in question, which is completed again with two differently oriented leaves, while the underlying first stem level slowly begins to lignify. The supporting structure symbolises 'qualitative', inwardlooking, structural growth, which secures the reached material extent. One begins to forget the cotyledons; these glide out of perception. Finally, buds develop in a longer process. These open their petals and bloom in a relatively short time to remain open for a long time. Thus, during the entire growth, different phases take place in which different functionalities of the whole organism are brought into focus.

This general paradigm of blossoming evolution - according to which one discipline and one developmental aspect goes through a latency period (flat beginning part of the curve), then a time of vigour (steep middle part of the curve) and then another latency on another level (flat end part of the curve) - can thus be an uncomplicated assumption. To open the path to interdisciplinary understanding, we proceed: although different causal relationships would always be valid and would have the character of a 'correct partial truth', in practice they would not become quantitatively effective, because other effects predominate in the respective development phases. Thus, the degree of suitability of different views, hence academic disciplines and worldviews for the description of overall reality, does change in the course of development phases.

\section{THINKING IN TRANSITIONS}

In order to adequately understand new ways, let us think in terms of transitions. More transitions than those described in Section 3.2 were presented in the same style in Ahamer (2018). A helpful graphical representation is to plot the rates of increase (in percent per year) against the (traditional) measure of GDP/cap in order to become graphically independent of historical time. The resulting data series represent the structural development of each state in a time span.

\subsection{The GCDB Method}

As a general approach, the GCDB method (= a graphically oriented trend analysis method based on the Global Change Data Base), which 
led to the discernment of the development dynamics of blossoming evolution, is defined as follows:

(a) Production of a 'red thread', that is a main chain of action through a complex field characterized by feedback as in Fig. 1;

(b) Representation of the arrows = processes as quotients that describe intensities; these are structural properties (and can conveniently be applied, for example, as $\mathrm{f}(\mathrm{GDP} / \mathrm{cap})$ );

(c) Graphical representation of the rates of change (mathematically the first time derivative) of these structuring quotients also as $f$ (GDP/cap);

(d) Considering and interpreting such graphs as to whether the rates of change in all states change evenly in a concerted manner (= second time derivative or curvature);

(e) Transitions are shown graphically as a change in the sign of the rate of change of the increase, i.e. (c) exceeds the zero line.

\subsection{The Example of Energy Transition}

The population transition that has already occurred, the land-use transition currently taking place, and the future assumed energy transfer are three examples and occasions for testing this formalized approach. These self-organizing dynamics probably govern the entire global energy problem! It is the energy transition (Fig. 4). The overall sign of the entire feedback loop is often clearly negative, so self-impeding feedback loops emerge, and thus saturation effects.

When viewing the global energy system, this saturating effect would even be beneficial for the protection of the climate because it accelerates pre-existing autopoietic (= self-directed) dynamic behaviour. Remark: To prevent policy-relevant misunderstandings, it should be clearly stated that this 'automatic' reduction of specific energy needs alone is far too low to reach climate protection goals!

In this endeavour of 'thinking in transitions', we already see that the combined global goal of 'lowering energy demand' - albeit too slowly - also corresponds to the trends of an 'already occurring development.'

\subsection{The Fundamental Forms of Trends}

But which waveform does a trend basically have? Is it purely 'geometrically growing', hence always exponentially growing, or even 'merely' linearly growing? No, we live in a limited world! Therefore, an increase 'beyond limited measures' in any material entity is impossible (only in structural or informational items such as 'consciousness' 
or 'quality' - hence these magnitudes may still be open as a last resort for growth).

For the discussion of trends, it is easier to consider the increases (delta $=$ the time derivative $=$ the oblique arrows in Fig. 2 ) according to the following table.

\begin{tabular}{|c|c|c|}
\hline $\begin{array}{l}\text { Level of } \\
\text { information signals }\end{array}$ & $\begin{array}{l}\text { Level of the } \\
\text { resulting formula archi- } \\
\text { tecture }\end{array}$ & $\begin{array}{c}\text { Level of the } \\
\text { waveform of the temporal } \\
\text { evolution of the parame- } \\
\text { ters }\end{array}$ \\
\hline $\begin{array}{l}\text { still no scarcity signal } \\
\text { is noticeable }\end{array}$ & $\rightarrow \underset{x}{\text { delta } x}=$ constant & $\rightarrow$ exponential \\
\hline $\begin{array}{l}\text { already a scarcity } \\
\text { signal is noticeable }\end{array}$ & $\begin{array}{c}\rightarrow \text { delta } x=\text { constant } . \\
\quad x .(1-x)\end{array}$ & $\rightarrow$ saturated \\
\hline
\end{tabular}

The result of a rate of increase determined by upper and lower limits is a sigma curve.

It is ultimately the shortages within a system that control longterm developments of that system!

Sustainability concepts mean scarcity management and are thus essentially an economy.

Fig. 2 actually conveys in a condensed, universally valid synopsis of fundamental effects for a new 'foundation of knowledge'. Actually, any parameter can be considered limited in principle, whether it is called earth population, global economic power or energy demand. The temporal movement of a parameter towards its upper limit means that its rate of increase slows down.

Such a dynamic structure is called 'transition' here.

\subsection{Phase-Dependent Laws}

However, in the different stages of growth, different laws obviously also apply: growth-oriented worldviews at the beginning (left in Fig. 2) and more saturation-orientated worldviews in the late phase (right in Fig. 2). Thus, the 'degrees of validity of description modes, that is, theories' are changing along evolutive developments - not by accident, but with an innate necessity.

When understanding this fundamental situation, how much greater the need for a discursive worldview!

Among other things, ecology supplies the 'limits' of growth (symbolically the end sizes $\mathrm{Z}$ ) and traditional economics supplies the 'motives' of growth (symbolically the starting values A).

It can be expected that at the end of a growth phase, 'structures' will form (e.g., institutions) similar to a plant stem lignified, in order to ensure the growth success of the previous year in a sustainable 
manner. This process would expire during the flat part of the saturation curve.

\section{Schematic enumeration of diverse developmental paradigms which also might represent diverse (economic and developmental) ideologies}

1. Ethically oriented globalisation concepts directed towards cultural and political consensus

2. Positive views of global development, classical development theories, exponential or over-exponential growth theories

\begin{tabular}{|l|}
\hline 3. Critical views such as dependency theory \\
\hline 4. Catastrophic theories or analyses of crises \\
\hline $\begin{array}{l}\text { 5. Cyclical theories including narrative approaches as vari- } \\
\text { ants }\end{array}$ \\
\hline 6. Saltion paris
\end{tabular}

6. Saturation paradigms, logistics curves, abatement scenarios, and post-growth concepts

7. Combined paradigms, namely integrating Kondratieff's cycles with on-going growth

8. Complexity paradigms in narrative or quantitative style, for example, as 'big history' or macro-history and more.

- The concept of 'blossoming evolution' means that saturation curves describe a given theme. The mathematical function is not a wave function (sin, cos) but a (Gaussian or similar) saturation curve. Hence, the controlling derivative is not the second but the first derivative, as in growth and decay functions. Each single process reaches a natural limit of saturation and by doing so, it ultimately slips out of attention. Another theme takes over the lead and represents a changed structure of '(ethical) values' by means of which the given civilisation optimises its evolutionary performance.
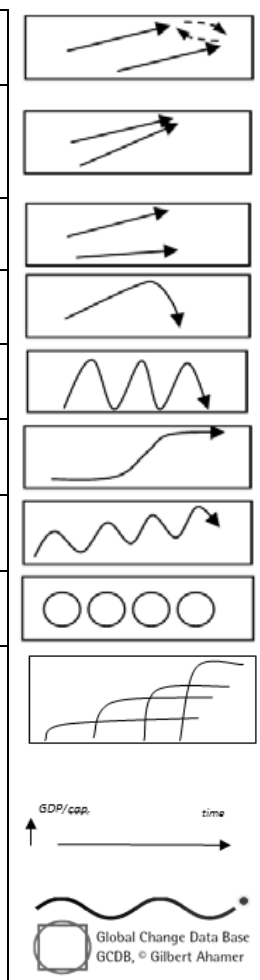

Source: changed after Ahamer (2014a, 2019).

The variance of the mathematical and formulaic appearance of above propositions for theories reflects the variance of understandings of development as such.

\section{THE TRANSITION OF GOALS AND MEANINGS}

Now follows the very speculative overall view, which continues the above consideration. The so-called 'jumps of targets' during ethical and civilisational evolution can be seen as follows (Fig. 3). 


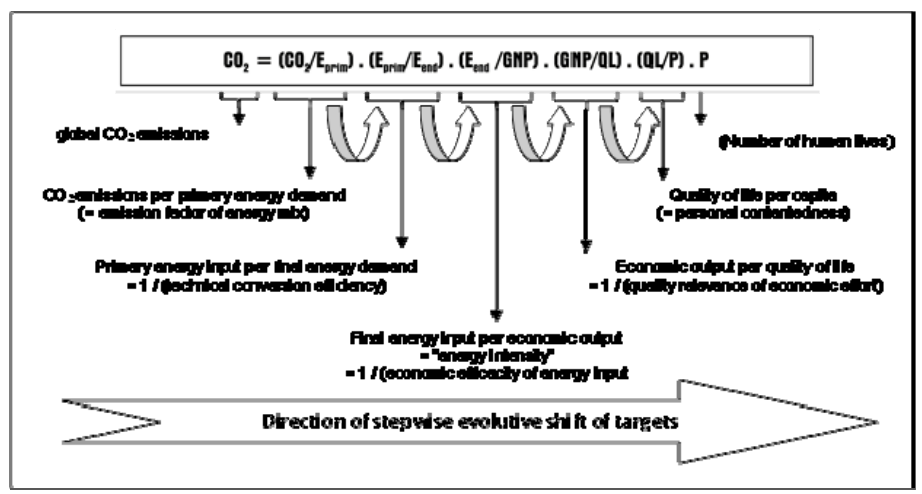

Fig. 3. Schematic representation of the fundamental shift of values along techno-socio-economic evolution. As values are reached and fulfilled (i.e., the corresponding measurement parameters saturate), the focus shifts to the right and new parameters become the focus of optimisation efforts (i.e., become new values, and thus optimisation goals)

The interpretation of Fig. 3 aims at illustrating that gradually, during techno-socioeconomic evolution (even if evolution is written in form of quotients only), some system parameters are the focus of the drive for optimisation. Within the same phase, other parameters may be comparatively out of the focus of optimisation, and thus seem to change comparatively less quickly. The focus of societal perception therefore walks with the focus of optimising speed - in Fig. 3 from left to right - and indeed moves from material flows to perception of meaning and sense.

On the left in Fig. 3 there are parameters which are more subject to the physical laws of matter conservation and therefore cannot grow without limit (such as carbon mass, energy content and financial volumes). Further to the right, however, there are qualitative parameters of information and meaning (and others are still likely to 'emerge' in the future) that are not necessarily subject to such fundamental barriers but can grow without strict principal limits.

In the course of civilizational evolution, developments can be additionally identified which can be regarded as 'target shifts' or 'target leaps,' namely the shift from collectively esteeming a given target as valuable, precious and needed by a majority of a country's population. Such we call target transitions. One example of a possible future social goal (after a dawning target transition) could be 'increasing the efficiency of economy's material activities for the quality of life.' This 
agrees with the trend towards a 'society of meaning' (his German term is 'Sinngesellschaft': Horx and Wippermann 1996: 184; Horx 1997: 57f, 107, 205, 2002: 259).

Taking the above diagnosis seriously, and when viewing the mathematical structure of the formula in Fig. 3, namely as a series of quotients, it becomes apparent that the values and paradigms are even completely reversed as they go through their generic development stages. The structural reason for this astonishing effect is that every parameter appears both as counter and as denominator in subsequent quotients in Fig. 3, and thereby undergoes two acts of optimisation: first in the role of a denominator and second in the role of a counter. Mathematically, it is quite clear that any such parameter is to be optimised in two opposite directions: historically earlier, it tends to grow (while being counted as 'desirable effect and result of a process') and historically later, it tends to fall (while being counted as 'effort in mastering a process').

Thus, even opposite development goals are experienced and implemented by any parameter appearing in a formula of type Fig. 3 . Thus, parameter values (by necessity, not by coincidence) go through a growth phase followed by a decrease phase, which mathematically means that their change rate is first positive and then negative. Consequently, the change between these two phases should be detectable by their change rate being around zero. All this does not occur as an exception and as an insignificant or incidental side effect, but as a principal effect of evolutionary structures to be expected in principle!

At the same time, the second derivative of a time series is understood as the parameter deflecting a trend from its usual continuation, and is therefore seen as 'value' materialised and implemented by a society.

In a nutshell, values in life (here understood to include the connotation of ethical values) are always context dependent. Having become aware of this basic truth makes it much easier to conduct subjectbased discourses, based on having recognised in principle that any 'truth' (e.g., a political, ethical or social judgement of an individual) is quite naturally dependent on the growth phase (of whatever compound or subset of socio-economic evolution). Thus, the sigma curve-like transitions become the icon of all life processes, including their attached or linked value systems.

At the same time, such an overarching paradigm offers a practical way of understanding that human visions actually and realistically determine real historic development (Lipton 2015), but humans are not victims. 


\section{COMPILATION OF PARADIGMS OF THE CONCEPT OF BLOSSOMING EVOLUTION}

The concept of blossoming evolution can have an integrative effect for questions on the topic of 'growth - environment - development' and also help to resolve the antagonism of the development-optimistic versus development-pessimistic concepts described above (Acemoglu and Ventura 2002; Alesina and Rodrik 1994; Pritchett 1997), because this systems-oriented and evolutionary worldview offers space for the following deliberations:

1. There is room for the concept of the growth phase itself (within one phase certain measures are useful, within another not) - without falling into the trap of biologisms.

2. It offers scope for an uncomplicated opening of the purely quantitative concept of growth to a qualitative concept of growth (which develops organically through autopoietic structure formation).

3. In an uncomplicated manner, it conceptually provides for saturation effects and even allows these to be expected in principle.

4. It takes into account the natural limitations of all life and all growth processes and can incorporate the 'distances to the ecosystem's capacity limits for taking a burden' and thus, analogously, the 'second time derivative of the measured variable.'

5. It incorporates structure formation (structogenesis) into the vocabulary, and understands this as an effect of the areas of validity of mathematical laws in which dependencies no longer grow mainly with exponential functions. Structures are understood to be formed later and as an intrinsic result of saturation states.

6. (Non)simultaneity effects are made understandable, because developmental time ( $=$ the physical-historical time renormalised to maturity levels of structure formation) is used as a key term instead of astronomic time.

7. The terms 'values' and 'value systems' are defined anew, which are related to the geometric curve curvature, that is the deflection of scenarios from their existing development direction.

8. It formally sees the 'values' as a (loose) correlate of the development process, which are established in the course of development without having to be grafted from another world of understanding. Ethics is thus simultaneously the result of the 'material production conditions' and their causally formative power, entirely in the sense of systems analysis, in which the 'either-or character' of cause or effect is dissolved by a reciprocal structure of mutual causation. 
9. It is understandable that for successful growth, several ("production') factors must work together jointly - because the autopoietically generated structure-forming effects (stemming from the previous phase) must have already taken place.

10. This is opposed to blunt control optimism, because any human or political measure is based on the (however moving) fundament of long-term trends which are taking place anyway.

11. Paradigm shift does not appear as an external effect occurring miraculously, unpredictably and externally imposed, but as an autopoietically developing and internally necessary process that always occurs in growth processes when the 'curve's turning point' (here = the border between growth logic and saturation logic) is reached. The saturation state after the turning point is coupled with structural change; this term 'change of inner structure' is thus no longer a foreign element in the building of understanding how systems evolve.

All in all, this text focuses on the embedding of developmental 'measures' in the already autopoietic evolutionary global dynamics. As a diplomatic measure, such multi-paradigmatic understanding should be trained via didactic sequences in the spirit of game play (Ahamer 2013a).

\section{CONCLUSIONS}

In order to overcome the widely felt inner unfamiliarity between the way the world is understood in the natural sciences and in economics, an introduction to the novel approach of blossoming evolution has been given in this text. This approach contains thought patterns from both worlds of understanding and is conceptually equidistant from both, so that it is hoped that this new concept will be equally easy and equally challenging to understand for representatives of both classical scientific traditions.

Differing and hence very divergent conceptions of development in globally operating institutions and the resulting divergent recommendations for action represent a very concrete requirement in order to conceptually facilitate the transition from one world view to another. The 'blossoming evolution' paradigm allows the merging of divergent paradigms because it adds the concept of phases, along which (seemingly stable) 'ideological truths' may change their efficacy in explaining actual historic global development. It can be expected that no peaceful practical-political solutions to the questions of development and climate protection will emerge unless the underlying worldviews are first harmonised. 


\section{REFERENCES}

Acemoglu, D., and Ventura, J. 2002. The World Income Distribution. Quarterly Journal of Economics 117 (2): 659-94.

Acemoglu, D., and Zilibotti, F. 1997. Was Prometheus Unbound by Chance? Risk, Diversification, and Growth. Journal of Political Economy 105 (4): 709-751.

Ades, A. F., and Glaeser, E. L. 1999. Evidence on Growth, Increasing Returns, and the Extent of the Market. Quarterly Journal of Economics 114 (3): $1025-1045$.

Ahamer, G. 1994. Influence of an Enhanced Use of Biomass for Energy on the $\mathrm{CO}_{2}$ Concentration in the Atmosphere. International Journal of Global Energy Issues 6 (1-2): 112-131. URL: https://www.researchgate.net/ publication/262914806_Influence_of_an_Enhanced_Use_of_Biomass_for Energy_on_the_CO2_Concentration_in_the_Atmosphere.

Ahamer, G. 2001. A Structured Basket of Models for Global Change. In Rautenstrauch, C., and Patig, S. (eds.), Environmental Information Systems in Industry and Public Administration (pp. 101-36). Hershey/PA: Idea Group Publishing. URL: https://www.researchgate.net/publication/ 262244805_A_Structured_Basket_of_Models_for_Global_Change.

Ahamer, G. 2013a. Game, Not Fight: Change Climate Change! Simulation and Gaming - An International Journal 44 (2-3): 272-301. DOI: 10.1177/ 1046878112470541. URL: https://www.researchgate.net/publication/3259 46856_Game_Not_Fight_Change_Climate_Change.

Ahamer, G. 2013b. Quality Assurance in Transnational Education Management - the Developmental 'Global Studies' Curriculum. In Mukerji, S., and Tripathi, P. (eds.), Handbook of Research on Transnational Higher Education Management. Vol. I, chapter 15 (pp. 259-302). Advances in Higher Education and Professional Development (AHEPD) Book Series, IGI Global Publishers, USA, 2014, DOI: 10.4018/978-1-4666-44588.ch015, URL: https://books.google.at/books?id=MuCWBQAAQBAJ. https://www.researchgate.net/publication/236847758_Quality_assurance_ in_transnational_education_management_-_the_developmental_Global_ Studies_curriculum.

Ahamer, G. 2013c. A Planet-Wide Information System. Campus-Wide Information Systems 30 (5): 369-378. DOI:10.1108/CWIS-08-2013-0032. URL: https://www.researchgate.net/publication/262731434_A_Planet-Wide_Information_System.

Ahamer, G. 2014a. Evolutionary Heyday: Generalization of Data on LongTerm Evolutionary Processes in the World. Moscow University Bulletin. Series 27. Globalistics and Geopoloitics 3-4: 25-35. Original in Russian (Ахамер Г. Эволюционный расцвет: обобщение данных о долгосрочных эволюционных процессах в мире. Вестник Московского университета, Серия XXVII: Глобалистика и геополитика, № 3/4, 25-35). 
URL: http://msupublishing.ru/index.php?option=com_content\&view=article \&id=356\&Itemid=100123; https://www.researchgate.net/publication/28764 7316_Evolutionary_bloom_collation_of_data_on_long-term_evolutionary_ process_in the _world_Ahamer_G_Evolucionnyj_rascvet_obobsenie_dan nyh_o_dolgosrocnyh_evolucionnyh_processah_v_mire.

Ahamer, G. 2014b. Kon-tiki: Spatio-Temporal Maps for Socio-Economic Sustainability. Journal for Multicultural Education 8 (3): 207-224. DOI: 10.1108/JME-05-2014-0022. URL: https://www.researchgate.net/publication/ 262797852_Kon-Tiki_spatio-temporal_maps_for_socio-economic_sustain ability.

Ahamer, G. 2018. = Applying Global Databases to Foresight for Energy and Land Use: The GCDB Method. Forsinpt 12 (4): 46-61. Original in Russian (Ахамер Г. Применение глобальных баз данных в Форсайтисследованиях энергетики и землепользования: метод GCDB. Форcaŭm 12 (4): 46-61). DOI: 10.17323/2500-2597.2018.4.46.61.

Ahamer, G. 2019. Mapping Global Dynamics - Geographic Perspectives from Local Pollution to Global Evolution. Dordrecht: Springer International Publishing. URL: https://link.springer.com/book/10.1007/978-3319-51704-9.

Ahamer, G., Jekel, T. 2010. Make a Change by Exchanging Views. In Mukerji, S., and Tripathi, P. (eds.), Cases on Transnational Learning and Technologically Enabled Environments (pp. 1-30). Hershey, New York: IGI Global. DOI: 10.4018/978-1-61520-749-7.ch001. URL: https://www. researchgate.net/publication/236964623_Make_a_Change_by_Exchanging Views.

Ahamer, G., and Kumpfmüller, K. 2013. Education and literature for Development in Responsibility - Partnership Hedges Globalization. In Mukerji, S. and Tripathi, P. (eds.), Handbook of Research on Transnational Higher Education Management. Vol. II, chapter 27 (pp. 526-584). Advances in Higher Education and Professional Development (AHEPD) Book Series, IGI Global Publishers, USA, 2014. URL: https://books. google.at/books?id=MuCWBQAAQBAJ. DOI: 10.4018/978-1-4666-44588.ch027. URL: https://www.researchgate.net/publication/236847697_Education_and_literature_for_development_in_responsibility_-_Partnership_ hedges_globalization.

Ahamer, G., and Mayer, J. 2013. Forward Looking: Structural Change and Institutions in Highest-Income Countries and Globally. Campus-Wide Information Systems 30 (5): 386-403. DOI: 10.1108/CWIS-08-2013-0034. URL: https://www.researchgate.net/publication/262731437_Forward_Looking__Structural_change_and_institutions_in_highest-income_countries_and globally.

Ahamer, G., and Mayer, J. 2014. Institutional Reorganisation can be Inspired by Forward-Looking Information Systems. Campus-Wide Information 
Systems 31 (2-3): 153-170. DOI: 10.1108/CWIS-09-2013-0046. URL: https://www.researchgate.net/publication/262731719_Institutional_reorga nisation_can_be_inspired_by_forward-looking_information_systems.

Ahamer, G., and Schrei, C. 2006. Exercise 'Technology Assessment' through a Gaming Procedure. Journal of Design Research 5 (2): 224-252. DOI 10.1504/JDR.2006.011364. URL: https://www.researchgate.net/publication/ 238065636_Exercise_'Technology_Assessment'_through_a_gaming_proc edure.

Alesina, A., and Rodrik, D. 1994. Distributive Politics and Economic Growth. Quarterly Journal of Economics 109 (2): 465-490.

Ayres, R. U. 1996. Limits to the Growth Paradigm. Ecological Economics 19 (2): 117-134.

Bardhan, P. 1993. Symposium on Democracy and Development. Journal of Economic Perspectives 7 (3): 45-49.

Barro, R. G. 1990. Government Spending in a Simple Model of Endogenous Growth. Journal of Political Economy 98 (5): 103-126.

Barro, R. J. 1991. Economic Growth in a Cross Section of Countries. Quarterly Journal of Economics 106 (2): 407-443.

Barro, R. J. 2001. Human Capital and Growth. American Economic Review 91 (2): 12-17.

Barro, R. J., and Sala-i-Martin, X. 1992. Convergence. Journal of Political Economy 100 (21): 223-251.

Baskin, K., and Bondarenko, D. M. 2018. The Role of Complexity Studies in the Emerging 'Processual' Worldview. Emergence: Complexity and Organization 20 (1): 1-12. DOI: 10.emerg/10.17357.c45145a20b3f2d1038 12be2e83d91f52. URL https://www.researchgate.net/publication/324694924 The_role_of_complexity_studies_in_the_emerging_processual_worldview.

Basu, S., and Weil, D. N. 1998. Appropriate Technology and Growth. Quarterly Journal of Economics 113 (4): 1025-1054.

Becker, G. S., and Murphy, K. M., and Tamura, R. 1990. Human Capital, Fertility, and Economic Growth. Journal of Political Economy 98 (5): 12-38.

Bernanke, B. S., and Gürkaynak, R. S. 2001. Is Growth Exogenous? Taking Mankiw, Romer, and Weil Seriously. NBER Macroeconomic Annals 16: $11-59$.

Bondarenko, D. M. 2007. Homoarchy as a Principle of Sociopolitical Organization: An introduction. Anthropos 102 (1): 187-199.

Bondarenko, D. M. 2009. The Social World's Parts and Whole: Globalization and the Future of Some Non-Western Cultures in the Civilization and World-System Theories Perspectives. In Sheffield, J. (ed.), Systemic Development: Local Solutions in a Global Environment (pp. 17-24). Litchfield Park, AZ: ISCE Publishing. 
Bondarenko, D. M. 2011. The Second Axial Age and Metamorphoses of Religious Consciousness in the 'Christian World'. Journal of Globalization Studies 2 (1): 113-136.

Bondarenko, D. M., Grinin, L. E., and Korotayev, A. V. 2002. Alternative Pathways of Social Evolution. Social Evolution \& History 1 (1): 54-79. URL: https://www.researchgate.net/publication/255586691_Alternative_ Pathways_of_Social_Evolution. Accessed 12 February 2019.

Capra, F. 2010. The Tao of Physics: An Exploration of the Parallels Between Modern Physics and Eastern Mysticism. Boston, MA: Shambhala.

Collier, P., and Gunning, J. W. 1999. Why has Africa Grown Slowly? Journal of Economic Perspectives 13 (3): 3-22.

Cole, M. A. 2003. Development, Trade, and the Environment: How Robust is the Environmental Kuznets Curve? Environment and Development Economics 8 (4): 557-580. URL: https://www.jstor.org/stable/44379595.

Darwin, R., Tsigas, M., Lewandrowski, J., and Raneses, A. 1996. Land Use and Cover in Ecological Economics. Ecological Economics 17 (3): 157-181.

De Long, J. B. 1999. Introduction to the Symposium on Business. Journal of Economic Perspectives 13 (2): 19-22.

De Long, J. B., Summers, L. H. 1991. Equipment Investment and Economic Growth. Quarterly Journal of Economics 106 (2): 445-502.

Descartes, R. 1997 [1632]. Discours de la méthode. French-German edition, ed. by Lüder Gäbe. Hamburg: Meiner.

Devereux, M. B., and Lapham, B. J. 1994. The Stability of Economic Integration and Endogenous Growth. Quarterly Journal of Economics 109 (2): 299-308.

EEA - European Environment Agency. 2005. Fifth Environmental Assessment Report. Copenhagen: European Environment Agency.

Ehrlich, I. 1990. The Problem of Development: An Introduction. Journal of Political Economy 98 (5): 2.

Ehrlich, I., and Lui, F. T. 1999. Bureaucratic Corruption and Endogenous Economic Growth. Journal of Political Economy 107 (6): 270-293.

Estevadeordal, A., Frantz, B., and Taylor, A. M. 2003. The Rise and Fall of World Trade, 1870-1939. Quarterly Journal of Economics 118 (2): 359-408.

Foster, A. D., Rosenzweig, M. R. 2003. Economic Growth and the Rise of Forests. Quarterly Journal of Economics 118 (1): 601-638.

Galileo Galilei. 1982 [1632] Dialogo sopra i due massimi sistemi del mondo, Tolemaico e Copernicano. Firenze. [Dialogue on the two main world systems: the Ptolemaic and the Copernican.] With a foreword by Albert Einstein. ed. by Roman Sexl. Stuttgart: Teubner.

Grossman, G. M., and Helpman, E. 1994. Endogenous Innovation in the Theory of Growth. Journal of Economic Perspectives 8 (1): 23-44. 
Grossman, G. M., and Krueger, A. B. 1995. Economic Growth and the Environment. Quarterly Journal of Economics 110 (2): 353-377.

Hart, R. 2002. Growth, Environment, and Culture - Encompassing Competing Ideologies in One 'New Growth' Model. Ecological Economics 40 (2): 253-267.

Hedenus, F., and Azar, Ch. 2005. Estimates of Trends in Global Income and Resource Inequalities. Ecological Economics 55 (3): 351-64.

Horx, M. 1997. Das Zukunftsmanifest. Wie wir uns auf das 21. Jahrhundert vorbereiten können. Düsseldorf: Econ.

Horx, M. 2002. Die acht Sphären der Zukunft. Wien: Signum.

Horx, M., and Wippermann, P. 1996. Was ist Trendforschung. Düsseldorf: Econ.

Huber, E., Rueschemeyer, D., and Stephens, J. D. 1993. The Impact of Economic Development on Democracy. Journal of Economic Perspectives 7 (3): 71-85.

ISI Thomson. 2005. ISI Thomson [Social] Science Citation Index [S]SCI. URL: http://www.thomsonisi.com.

Islam, N. 1995. Growth Empirics: A Panel Data Approach. Quarterly Journal of Economics 110 (4): 1127-70.

Islam, N. 1998. Growth Empirics: A Panel Data Approach - A reply. Quarterly Journal of Economics 113 (1): 325-329.

Islam, S. M. N., Munasinghe, M., and Clarke, M. 2003. Making Long-Term Economic Growth More Sustainable: Evaluating the costs and Benefits Ecological Economics 47 (2-3): 149-166.

Jones, Ch. I. 1995. Time Series Tests of Endogenous Growth Models. Quarterly Journal of Economics 110 (2): 495-525.

Jones, Ch. I. 1997. On the Evolution of the World Income Distribution. Journal of Economic Perspectives 11 (3): 19-36.

Jones, Ch. I., and Williams, J. C. 1998. Measuring the Social Return to R\&D. Quarterly Journal of Economics 113 (4): 1119-1135.

King, R. G., and Rebelo, S. 1990. Püblic Policy and Economic Growth: Developing Neoclassical Implications. Journal of Political Economy 98 (5): $126-151$.

King, R., and Levine, R. 1993. Finance and Growth: Schumpeter might be Right. Quarterly Journal of Economics 108 (3): 717-737.

Kremer, M. 1993. Population Growth and Technological Change: One million B.C. to 1990. Quarterly Journal of Economics, 108 (3): 681-716.

Krugman, P., and Venables, A. J. 1995. Globalization and the Inequality of Nations. Quarterly Journal of Economics, 110 (4): 857-880. 
Lipton, B. H. 2015. The Biology of Belief. Unleashing the Power of Consciousness, Matter \& Miracles. Hay House, Carlsbad, California, ISBN 978-1-4019-4891-7.

Mankiw, N. G., Romer, D., and Weil, D. N. 1992. A Contribution to the Empirics of Economic Growth. Quarterly Journal of Economics 107 (2): $407-438$.

Marchetti, C., and Nakićenović, N. 1979. The Dynamics of Energy Systems and the Logistic Substitution Model. Laxenburg: International Institute for Applied Systems Analysis.

Mauro, P. 1995. Corruption and Growth. Quarterly Journal of Economics 110 (3): 681-712.

Morse, S. 2003. For Better or for Worse, till the Human Development Index Do Us Part? Ecological Economics 45 (2): 281-296.

Moser, F. 2017. Beyond Einstein's visions. International Journal of Foresight and Innovation Policy, 12 (1-3): 37-46. DOI:10.1504/IJFIP.2017.085818.

Moser, F. 2018a. Beyond Sigmund Freud's Totem and Taboo Vision for the Future - the Omnipotence of Thought. International Journal of Foresight and Innovation Policy, 13 (3-4): 187-194. DOI: 10.1504/IJFIP.2018.097083.

Moser, F. 2018b. The Conception of Human Beingness at Different Times, in Different Cultures, up to the Present. International Journal of Foresight and Innovation Policy, 13 (3-4): 263-279. DOI: 10.1504/IJFIP.2018. 097085.

Nakićenović, N. 1997. Environment, Energy, and Economy: Strategies for Sustainability. UNU-Press, http://www.unu.edu/unupress/unupbooks/uu17 ee/uu17ee00.htm. Accessed on July 7, 2018.

Nonneman, W., and Vanhoudt, P. 1996. A Further Augmentation of the Solow Model and the Empirics of Economic Growth for OECD Countries. Quarterly Journal of Economics, 111 (3): 943-953.

Novy, A. 2008. Doppelter Dialog - Zur Didaktik der 4. Österreichischen Entwicklungstagung. URL: http://www.paulofreirezentrum.at/index. php?Art_ID=601. Accessed July 7, 2018.

Pack, H. 1994. Endogenous Growth Theory: Intellectual Appeal and Empirical Shortcomings. Journal of Economic Perspectives, 8 (1): 55-72.

Pritchett, L. 1997. Divergence, Big Time. Journal of Economic Perspectives 11 (3): 3-17.

Przeworsky, A., and Limongi, F. 1993. Political Regime and Economic Growth. Journal of Economic Perspectives 7 (3): 51-69.

Rammel, Ch., and Bergh, J. van den 2003. Evolutionary Policies for Sustainable Development: Adaptive Flexibility and Risk Minimising. Ecological Economics 47 (2-3): 121-133. 
Rosenzweig, M. R. 1990. Population Growth and Human Capital Investments: Theory and Evidence. Journal of Political Economy, 98 (5): 38-71.

Rivera-Batiz, Luis A.; Romer, Paul M. (1991). Economic integration and endogenous growth. Quarterly Journal of Economics, 106(2), 531-555.

Rivera-Batiz, L., and Romer, P. 1994. Economic Integration and Endogenous Growth: An Addendum. Quarterly Journal of Economics 109: 307-308.

Romer, Ch. D. 1991. The Cyclical Behavior of Individual Production Series, 1889-1984. Quarterly Journal of Economics, 106 (1): 1-31.

Romer, P. M. 1990. Endogenous Technological Change. Journal of Political Economy 98 (5): 71-103.

Romer, P. M. 1994. The Origins of Endogenous Growth. Journal of Economic Perspectives, 8 (1): 3-22.

Scully, G. W. 1988. The Institutional Framework and Economic Development. Journal of Political Economy, 96 (3): 652-662.

Solow, R. M. 1994. Perspectives on Growth Theory. The Journal of Economic Perspectives, 8 (1): 45-54. URL: https://www.jstor.org/stable/2138150.

Stokey, N. L. 1991. Human Capital, Product Quality, and Growth. Quarterly Journal of Economics, 106 (2): 587-616.

Teilhard de Chardin, P. 1969. Der Mensch im Kosmos. München: Beck.

Temple, J., and Johnson, P. A. 1998. Social Capability and Economic Growth. Quarterly Journal of Economics, 113 (3): 965-990.

Whitehead, A. N. 1979. Process and Reality: An Essay in Cosmology. New York: The Free Press.

Vernadsky, V. 1986 [1926]. The Biosphere. English translations published by: Oracle, AZ, Synergetic Press, , ISBN 0-907791-11-5, 86 pp. tr. David B. Langmuir, ed. Mark A. S. McMenamin, New York, Copernicus, 1997, ISBN 0-387-98268-X.

West, K. D. 1990. The Sources of Fluctuations in Aggregate Inventories and GNP. Quarterly Journal of Economics, 105 (4): 939-971.

Young, A. 1993. Substitution and Complementarity in Endogenous Innovation. Quarterly Journal of Economics, 108 (3): 775-807.

Zarnowitz, V. 1985. Recent Work on Business Cycles in Historical Perspective: A Review of Theories and Evidence. Journal of Economic Literature, 23 (2): 523-580.

Zarnowitz, V. 1999. Theory and History behind Business Cycles: Are the 1990s the Onset of a Colden Age. Journal of Economic Perspectives, 13 (2): 69-90.

Zeira, J. 1998. Workers, Machines, and Economic Growth. Quarterly Journal of Economics, 113 (4): 1091-1117. 


\section{Appendix}

Appendix 1

\section{A short summary of a detailed literature analysis on 'growth theories'}

According to the statements of some one hundred publications on economic development and economic performance, there are the following main influences. In other words, the below-mentioned items answer to the question 'How can we increase growth?' - or 'To reach the goal of GDP, what would we have to do?' The following answers are provided:

\section{Increase international trade}

1. Acemoglu / Ventura (2002): The world income distribution depends on the degree of openness to international trade and the extent of specialisation

2. Ades / Glaeser (1999): Rising earnings in larger markets and greater openness of the economy to trade

3. Estevadeordal et al. (2003): World Trade, as in the 'First Globalization' 1870-1914.

\section{Increase international integration}

1. Devereux / Lapham (1994): (international) economic integration (increases and accelerates growth)

2. Rivera-Batiz / Romer (1991, 1994); Devereux / Lapham (1994): economic integration

\section{Invest in so-called 'human capital'}

1. Barro (1991, 2001): 'human capital' (described by school attendance data) and political stability promote growth; mark distortions inhibit it

2. Mankiw et al. (1992): Solow's neoclassical standard model, to which 'human and physical capital' are added as terms, explains growth how

3. Nonneman / VanHoudt (1996): add further accumulation of know-

4. Stokey (1991): Human capital and product quality

5. Islam (1995), Rosenzweig (1990), Becker et al. (1990): Hypotheses on growth include school and education

4. Invest in research and development $(R \& D)$

1. Jones / Williams (1998): R \& D yields 'social returns'

2. Grossman / Helpman (1994): Endogenous (self- proclaimed) innovation generates growth par excellence

\section{Invest in technology}

1. Basu / Weil (1998), suitable technologies generate growth

2. Young (1993): New technologies are both creative and destructive of old economic structures 
3. Zeira (1998): New technologies are diffusing slowly, resulting in higher equipment costs and lower labour costs

4. Romer (1990): 'Endogenous Technological Change' (endogenous technological change)

6. Brings investments in physical capital

1. de Long anв Summers (1991): Investment in machinery

7. Build financial systems

1. King / Levine (1993): The financial systems bring about economic growth through their services

\section{Public policy}

1. King / Rebelo (1990): Politics

2. Barro (1990): Government Spending

9. Promote a more even income distribution

1. Alesina / Rodrik (1994), Distribution Policy: Growth is associated with a more even income distribution within a society (e.g. described by the Gini coefficient)

10. Promote institutions and democracy

1. Mauro (1995): Absence of corruption, bureaucratic routine and the efficiency of the judiciary promote growth

2. Temple / Johnson (1998): Social performance (measured by the Adelman- Morris index) promotes growth

3. Huber et al. (1993): Economic development promotes democracy. The well-known Konnex democracy $=>$ GDP is examined here the other way around

4. Przeworsky / Limongi (1993); Bardhan (1993): Democratic political regimes favour economic growth

5. Scully (1988), institutional frameworks are essential

6. Ehrlich / Lui (1999), bureaucratic corruption hinders growth

7. See also the literature analysis of other authors, according to which: Convergence is a 'balance in motion' and technological progress is not everywhere equally 'manna from heaven'

\section{Endogenous growth is the sole explanation}

1. Jones (1995) with time series analysis; King / Levine (1993); Pack (1994): Inadequacies of the 'endogenous growth theory'

2. Romer, P. (1994): Causes of Endogenous Growth

3. Bernanke / Gürkaynak (2001), Solow (1994): Perspectives of Growth Theory

12. Often, in the search for answers, only mathematical models are studied instead of verifiable reality:

1. Alesina / Rodrik (1994): Distribution Policy and Growth. 
Other important dependencies of GDP / cap:

13. Goes parallel with population as such:

1. Kremer (1993): High population means more potential innovators

2. Rosenzweig (1990): Population growth and human capital

3. Becker et al. (1990): Fertility and Growth

14. Goes in parallel with the distance to the civilisation centres:

1. Krugman / Venables (1995: 859): The effect of the distance from the centre in a geographic core / periphery arrangement: the effect is twofold, depending on the globalisation phase. First: growth of the core at the expense of the periphery, reversed in the final phase.

\section{Goes parallel with forest / land cover:}

1. Darwin et al. (1996): Land use and plant cover determine economic growth

2. Foster / Rosenzweig (2003): The increase in forest areas correlates with GDP growth in open economies with a different sign compared to closed economies

16. Is parallel with environmental impact / quality or just not or just Kuznets curves-like (the application of the U-shaped 'Environmental Kuznets Curve' EKC content remains controversial)

1. Grossman / Krueger (1995): The environmental quality (air, water, etc.) shows deterioration in the initial phase, followed by a period of improvement

2. Hart (2002: 253): Growth, environment and culture; Cole (2003): Trade, Emission, EKC

3. Islam et al. (2003): Growth and sustainability: new term 'sustainomics'

\section{Diversification of risk}

1. Acemoglu / Zilibotti (1997): Market imperfections such as risk or diversification

\section{8. (Merely) cyclical effects}

1. Romer, Ch. (1991): describes cyclically behaving production series

2. West (1990), Sources of Fluctuations in GDP

3. Zarnowitz (1985, 1999), de Long (1999): regular historical economic cycles

19. The crucial question: 'Is there convergence or divergence?' (comes to different conclusions as expected):

1. Hedenus / Azar (2005): Global Unequal Distribution of Income and Resources.

2. Pritchett (1997): Divergence is Reality 
3. Jones (1997): Data on global income distribution point to divergence rather than convergence

4. Barro / Sala-i-Martin (1992): Convergence applies to the US states

20. Complete illustrations and theoretical justifications provide:

1. Jones (1995): Time series 1860-1990 serve as a test for models of endogenous growth and result in stable growth rates for the USA, for example

2. Morse (2003): The deterministic genetic hypothesis is an explanatory method for economic development (to be simplified)

3. Ehrlich (1990): A review and a conference as an introduction to the problem of development

\section{Good overviews:}

Islam (1995):

1. provide overall high-quality reflection and rare mature descriptions of the current research process regarding growth theories

2. perform a 'panel data' method by (methodologically compatible with the GCDB method)

3. distinguish the term 'convergence' in terms of level or growth rate (p. 1129)

4. call for more activism in politics (p. 1128). concepts!

22. Islam (1998): very good six-stage representation of the model

23. The basic question 'Is growth ever needed?'

1. Ayres (1996): Limits of the growth paradigm: Economic growth (as conventionally measured) is not and has never been the most important contribution to increasing human welfare

\section{An evolutionary approach takes:}

1. Rammel / Bergh (2003): Evolutionary Economics

2. see also the first 'Schumpeter Symposium' in Graz with a summary of the approach of the evolutionary economy

\section{The case study Africa considers:}

1. Collier / Gunning (1999): The question 'Why did Africa grow so slowly?' has several dimensions: are the reasons to be found in politics or fate? Are they domestic or external?

The above description is intended to open the view on the richness of detail of previous occupations with 'growth,' in the course of which a quantitative description of many aspects has been attempted. However, most of the time the impression of incomplete conception remains, namely that only one or very few sub-mechanisms of the entire topic are perceived. 


\section{The energy demand as diagnosed by the GCDB}

It is the objective of the GCDB to provide bundles of time series over several decades for every country. Fig. 4 shows the example of energy demand per inhabitant for citizens of every state separately and Fig. 5 analogously the per capita energy demand. In order to provide a visible data structure, the GCDB renormalizes data from the time axis to the axis of economic development GDP/cap).

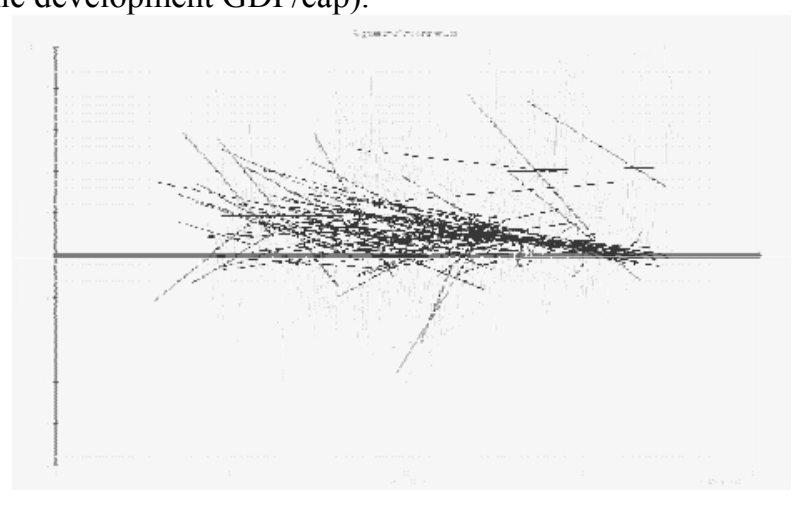

Fig. 4. Development of the annual growth rate of absolute final energy demand in Petajoule PJ $\left(E\right.$ final $\left.=E_{f}\right)$ as a function of the economic level measured as GDP/cap. This measure apparently decreases during techno-socio-economic evolution. Hence, final energy demand seems to steer into saturation worldwide

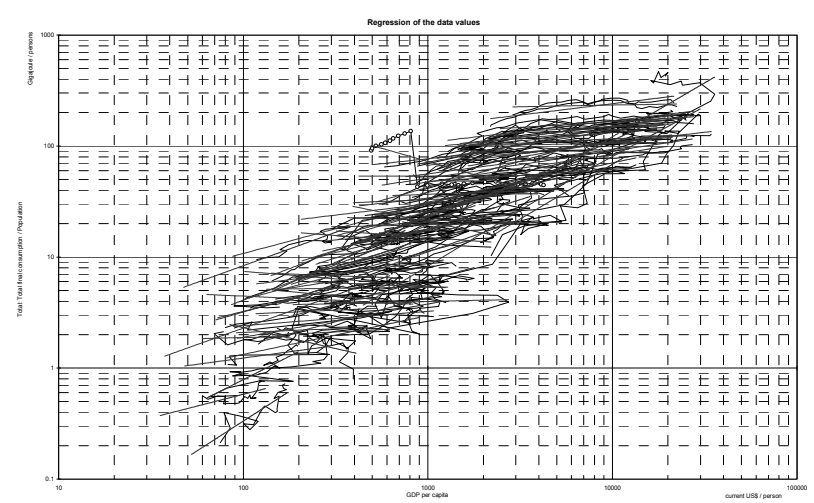

Fig. 5. Representation of the final energy demand per capita (Ef / cap) as a function of (GDP/cap) that tends towards saturation in countries with the highest GDP/cap.

In the insert only the red trend lines are visible 